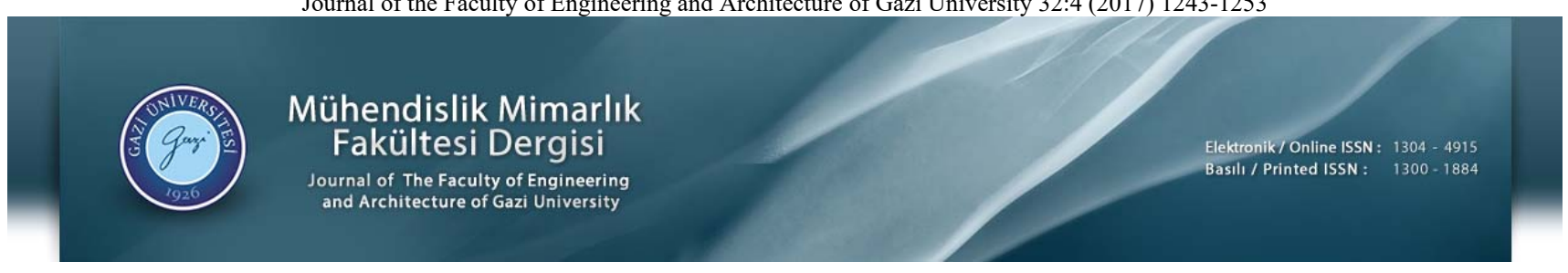

\title{
Keban ve Karakaya Barajları arası Firat Nehri'nin kıyı sedimentleri ve su jeokimyası özellikleri
}

Leyla Kalender(D), Gamze Aytimur(D)

Fırat Üniversitesi, Mühendislik Fakültesi, Jeoloji Mühendisliği Bölümü, 23119, Elazı̆̆, Türkiye

Ö N E Ç I K A N L A R

- $\quad$ Fırat Nehri su ve sedimanlarının iz element dağılım ilişkisi

- Neodimium ve stronsyum izotopik bileşim oranları

- Fırat Nehir sedimanlarının kaynak kayaçlarının belirlenmesi

Makale Bilgileri

Geliș: 09.08.2016

Kabul: 27.10.2016

DOI:

$10.17341 /$ gazimmfd. 369673

Anahtar Kelimeler:

Firat Nehri,

sediman ve su jeokimyas1,

$\mathrm{Nd}-\mathrm{Sr}$ izotopları

\section{ÖZET}

Bu çalışmanın amacı, Fırat Nehri kıyı sediman ve su örneklerinde ana element, iz element konsantrasyonları ve bazı sediman örneklerinde ise Sr-Nd izotopik bileşim oranlarını kullanarak, element dağılımları üzerinde, kaynak kayaç etkisinin belirlenmesidir. Nehir sedimanlarındaki yüksek $\mathrm{Ag}, \mathrm{Pb}, \mathrm{Mn}, \mathrm{Hg}, \mathrm{Cu}, \mathrm{Ba}, \mathrm{Au}, \mathrm{Mo}$, $\mathrm{As}, \mathrm{Hg}$ ve $\mathrm{Zn}$ derişimlerinin, terk edilmiş Keban maden yatağı eski imalat pasalarından kaynaklandığı düşünülmektedir. Bu çalışmada, nehir suyu ve sedimanların ortalama metal içeriği karşılaştırılmış ve bazı stabil ağır metallerin (Ba, Cr, Hf ve Zr), nehir suyundaki içeriğinin, diğer metallere göre daha düşük olduğu, bu metallerin yüksek yoğunlukları nedeniyle, stabil oksit ve hidroksitlerini oluşturmuş olabileceği düşünülmektedir. Fırat Nehir sedimanlarında, $143 \mathrm{Nd} / 144 \mathrm{Nd}$ ve $87 \mathrm{Sr} / 86 \mathrm{Sr}$ izotop bileşim oranları, sırasıyla 0,7057- 0,7048 ve 0,512836-0,512654 değerleri aralığındadır. Nd ve Sr izotop bileşim oranları, neodimyumun, granodiyoritlerden, stronsyumun ise karbonatça zengin meta-sedimanlardan kaynaklandığını göstermektedir. $87 \mathrm{Sr} / 86 \mathrm{Sr}$ ve $\mathrm{Ca} / \mathrm{Sr}$ oranları, subtropikal iklim koşullarında, evaporitik oluşumların geliştiğini düşündürmektedir. Elde edilen bulgular, Fırat Nehir sediman ve sularının kimyasal bileşimlerinde, hidromorfik dağılımın, mekanik dağılımdan daha etkili olduğunu göstermektedir.

\section{Geochemical characterization of shore sediments and water of the Euphrates River between Keban and Karakaya Dams}

\section{H I G H L I G H T S}

- $\quad$ Trace element distribution relation of the Euphrates River water and sediments

- Neodymium and strontium isotopic composition ratios

- Determination of source rocks of Euphrates River sediments

Article Info

Received: 09.08.2016

Accepted: 27.10 .2016

DOI:

10.17341/gazimmfd.369673

Keywords:

Euphrates River, sediment and water geochemistry, $\mathrm{Nd}-\mathrm{Sr}$ isotopes

\section{ABSTRACT}

The aim of this study is to determine the effects of the source rocks on distribution of major and trace element concentrations in the sediment and water samples from the Euphrates River, and $\mathrm{Sr}-\mathrm{Nd}$ isotopic composition ratios in some of the sediments. The high concentration of $\mathrm{Ag}, \mathrm{As}, \mathrm{Pb}, \mathrm{Mn}, \mathrm{Hg}, \mathrm{Cu}, \mathrm{Ba}, \mathrm{Au}, \mathrm{Mo}, \mathrm{Hg}$ and $\mathrm{Zn}$ in the river sediments may be considered to be sourced from wastes from the abandoned Keban mine deposit. In the study, the mean content of metals in the river water and river sediments were compared, and element concentrations in the river waters of some stable heavy metals (Ba, Cr, Hf and $\mathrm{Zr}$ ) are lower than the other metal concentrations in studied river sediments and so they may be formed stable oxides and/or hydroxides, and thus are considered insoluble due to high density. The $143 \mathrm{Nd} / 144 \mathrm{Nd}$ and $87 \mathrm{Sr} / 86 \mathrm{Sr}$ isotopic compositions $0,7057-0,7048$ and $0,512836-0,512654$, respectively show that the source rocks for $\mathrm{Nd}$ and $\mathrm{Sr}$ are granodioritic and carbonate-rich meta-sedimentary rocks, respectively. $87 \mathrm{Sr} / 86 \mathrm{Sr}$ ratio and $\mathrm{Ca} / \mathrm{Sr}$ ratio indicate evaporite formations due to subtropical conditions. The obtained results show that hydromorphic distribution is a more effective factor on the studied river sediments than mechanical distribution.

\footnotetext{
*Sorumlu Yazar/Corresponding Author: leylakalender@firat.edu.tr / Tel: +90 5425758872
} 


\section{GÍRIŞ (INTRODUCTION)}

Çalışma alanı ve yakın çevresinde genel jeolojik, petrografik ve maden yataklarına yönelik birçok çalışma bulunmaktadır. Keban Metamorfitlerinin Permo- Triyas aralığında çökeldiğini ve Senoniyen yaşlı, Elazı̆̆ Mağmatitleri'nin, Keban Metamorfitleri'ni yer yer tektonik ve intrüsif olarak kestiği belirtilmiştir [1, 2]. Üst Kretase yaşlı Elazı̆̆ Magmatitleri ile Keban Metamorfitlerinin tektonik dokanağında yapılan çalışmalar daha çok düşük açılı bindirme zonlarına dikkat çekilmektedir [3, 4]. Elazı ̆ Magmatitlerine ait derinlik, yarı derinlik ve yüzey kayaçlarının, Üst Kretase sonu tektonik hareketlerle Keban Metamorfitleri tarafından üzerlendiği belirtilmiştir $[5,6]$. Elazı̆̆ Magmatitleri'nin jeokimyasal ve petrolojik incelemeleri sonucu, birimin, diyorit, monzodiyorit kuvars diyorit ve tonalitten oluşan derinlik kayaçları, bazalt, andezit ve andezitik piroklastitler gibi yüzey kayaçlarından oluştuğunu belirtilmiştir [7, 8]. Keban yöresinde bazaltik ve andezitik birimler görülmektedir [9]. Fırat Nehri akım yönü boyunca, Malatya civarında yapılan jeolojik çalışmalar, bölgedeki magmatizmanın bazik evre ile başladığını ve sonrasında asidik bileşime geçildiğini göstermektedir [10]. Kömürhan Ofiyoliti ile Baskil Magmatitleri arasında güneyde tektonik ilişki izlenmektedir $[11,12]$. Çalışma alanı içerisinde yapılan sedimantolojik çalışmalar; Eosen stratigrafisinin, daha önceki bütün çalışmalarda belirtilenin aksine Üst Paleosen-Alt Eosen yaşlı Seske Formasyonu ile Orta Eosen yaşlı Kırkgeçit Formasyonu arasındaki dokanağın uyumlu olduğunu göstermektedir [13]. Literatür kapsamında maden atıkları ve nehir sedimanlarına etkileri üzerine birçok çalışma bulunmaktadır $[14,15]$.

$\mathrm{Bu}$ çalışmalar pasaların yüzeysel işlevler ile ayrışmaları yolu ile jeokimyasal dağılıma neden olmaktadır [16,17]. Fırat Nehir sedimanlarındaki nadir toprak element (NTE) dağılımlarının daha çok üst kıtasal kabuğa yakın olduğu, tektonik zonların etkisiyle yüksek oranda altere magmatik kayaç etkisi görülmektedir [18]. Fırat Nehri'nin bir kolu olan, Geli Dere sediman ve su jeokimyası ilk kez Kalender ve Çiçek Uçar [19] tarafından çalışılmış ve terkedilmiş

Keban Polimetalik maden yatağının Fırat Nehri akım yönü boyunca etkisinin belirlenmesi gereği ortaya çıkmıştır. Literatür kapsamında, aluviyal ve fluviyal sistemler içerisinde, sedimanların kaynak kayaçlarının belirlenmesi için Neodimium izotop bileşim oranlarının kullanılması üzerine birçok çalışma bulunmaktadır [20, 21]. Buna ilaveten göl sedimanlarında neodimium izotop verileri, kaynak kayaç araştırmalarına katkı sağlamıştır [22]. Ayrıca denizel sedimanlarda stronsyum izotop çalışmaları ile elde edilen bulgular granodiyoritlerin izotop bileşim oranları ile karşılaştırılarak kaynak kayaçı belirlemeye yönelik çalışmalar yapılmıştır [23, 24]. Bu çalışma ile, Keban Karakaya barajları arasında Firat Nehir sediman ve su kimyası verileri, jeokimyasal bir bakış açısıyla değerlendirilerek aynı zamanda, Nd-Sr izotop bileşimleri yardımıyla kaynak kayaç kökeni yorumlanabilecektir.

\section{JEOLOJİ (GEOLOGY)}

Çalışma alanı, Keban ve Karakaya Barajı, 3841'32.48"K $38^{\circ} 14^{\prime} 24.10^{\prime \prime K}$ enlem ve $39^{\circ} 56^{\prime} 4.59^{\prime \prime}$ D $39^{\circ} 8^{\prime} 13.41^{\prime \prime D}$ boylamları ve Malatya K41 a3 ve K41 a4 paftaları içinde yer almaktadır (Şekil 1).

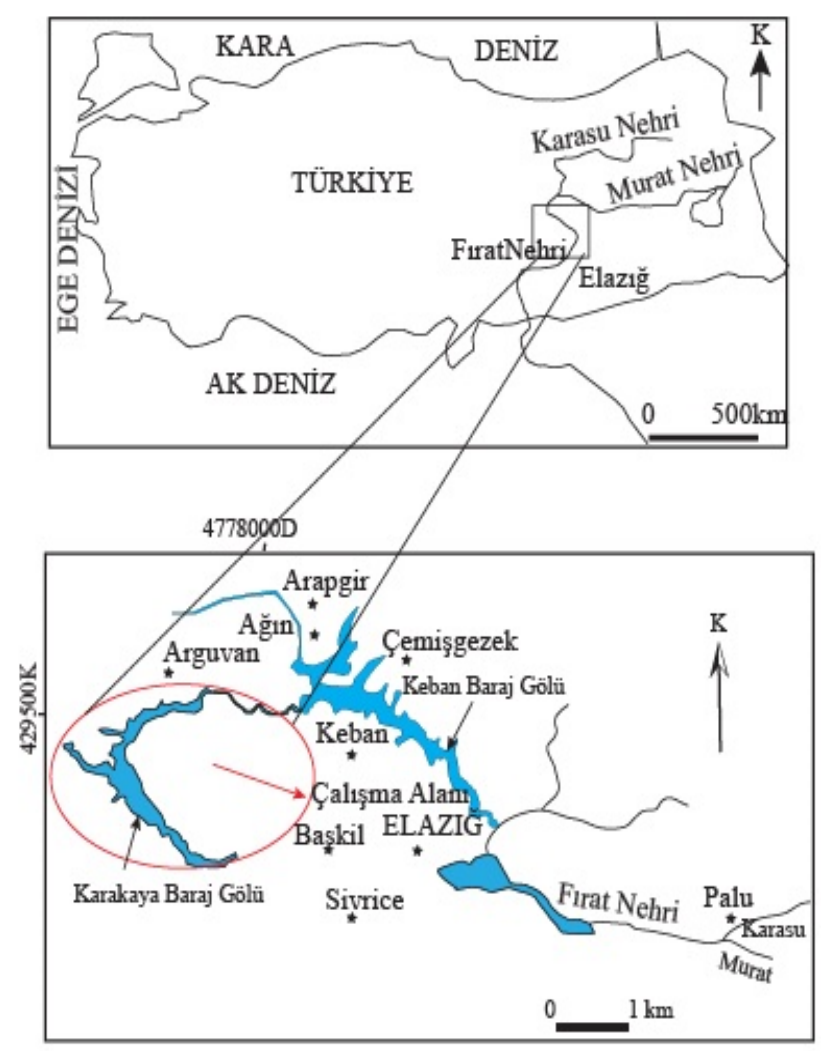

Şekil 1. İnceleme alanının yer bulduru haritası (Location map of the study area)

Çalışma alanı ve yakın çevresinde yaşlıdan gence doğru Keban Metamorfitleri (Permo Triyas), Elazı $\breve{g}$ Plütonitleri (Üst Kretase), Elazı̆̆ Volkanitleri (Üst Kretase), Seske Formasyonu (Üst Paleosen-Alt Eosen), Maden Karmaşı̆̆ (Orta Eosen), Kırkgeçit Formasyonu (Orta Eosen), Alibonca Formasyonu (Üst Oligosen-Alt Miyosen) Karabakır Formasyonu (Üst Miyosen- Alt Pliyosen), ve alüvyal malzeme (Kuvaterner) yüzeylemektedir (Şekil 2). İnceleme alanı ve yakın civarında gözlenen Üst Kretase yaşlı tektonomagmatik birimlerin (Baskil Magmatitleri ve Elazı ̆̆ Magmatitleri) oluştuğu jeodinamik ortamın, And tipi aktif kıta kenarı ürünleri olduğu ve Baskil Magmatitlerinin eşlenikleri olduğu bildirilmektedir [25]. Aynı zamanda, Elazı̆̆ Magmatitlerinin, Kömürhan Ofiyoliti üzerinde dalma-batmanın geç evrede geliştiği düşünülmektedir [26, 27]. Yukarıda belirtilen tüm birimleri, Keban Barajından, Karakaya Barajına kadar Fırat Nehri akım yönü boyunca görmek mümkündür. $\mathrm{Bu}$ nedenle, nehir sediman ve su kimyası üzerinde etkili litolojiyi belirlemek, bu çalışmanın odağında yer almaktadır. 


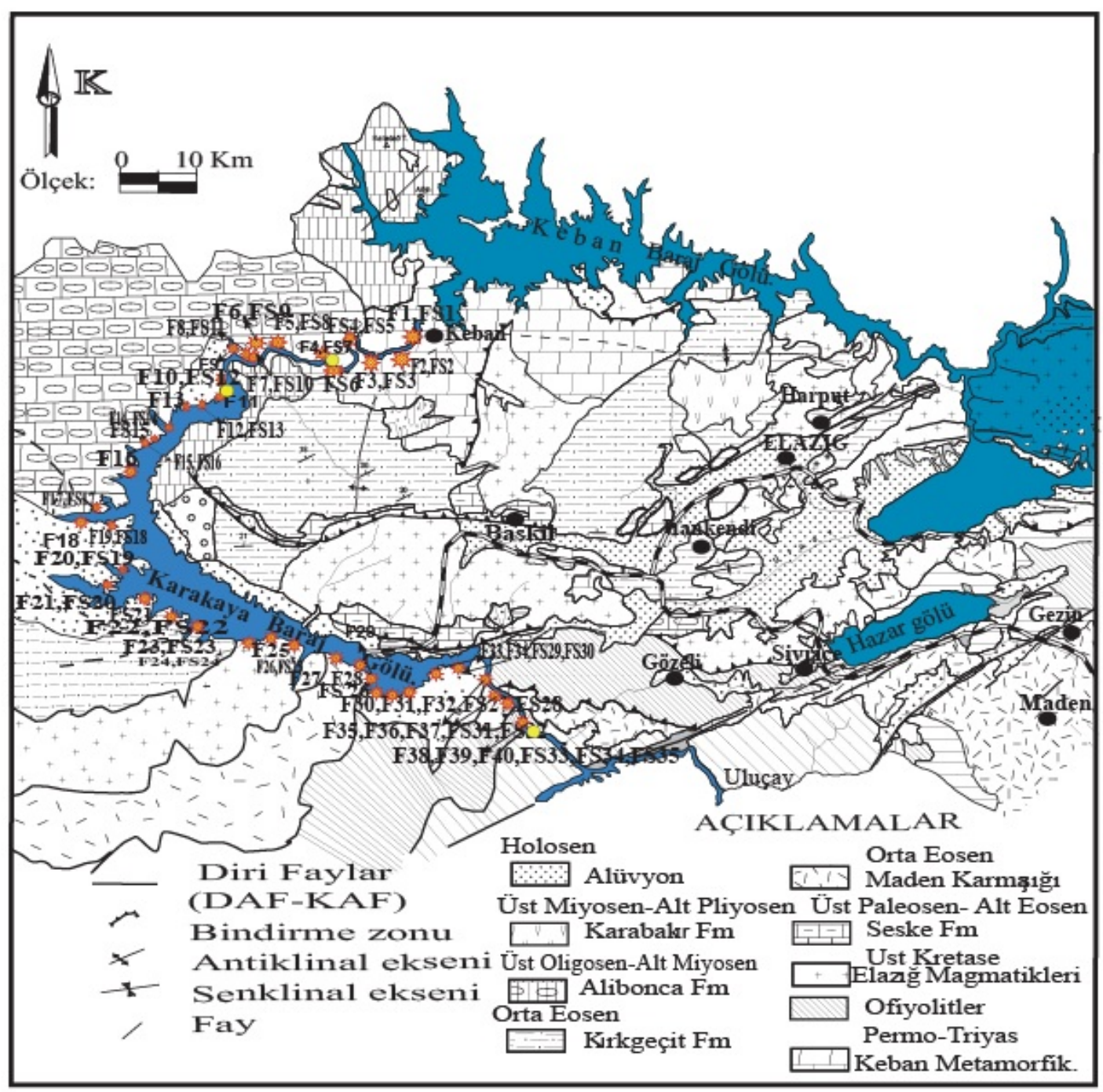

Şekil 2. İnceleme alanının jeoloji haritası (MTA [28]'den değiştirilerek alınmıştır) 洛: sediman ve su örnek alım noktaları : İzotop analizleri için örnek alım noktaları

(Geologic map of the study area, (modified from MTA [28]) 沵: sediment and water sample sites $\bigcirc$ : Sediment sample sites for isotope analysis

\section{ANALITIK YÖNTEMLER (ANALYTICAL METHODS)}

\subsection{Nehir Sediman Örneklerinin Kimyasal Analiz Yöntemleri}

(Chemical Analysis Methods of River Sediment Samples)

Bu çalışmada, önceki çalışmalar ışı̆̆ında [19, 29], 40 adet kıy1 sediman örneği (F1'den F40'a kadar) alınmıştır (Şekil 2). Alınan yaklaşık $2 \mathrm{Kg}$ ağırlığındaki nehir sediman örnekleri naylon torbalara konularak her biri numaralandırılmış ve oda sıcaklığında kurutulmuşlardır. Kurutulduktan sonra, $75 \mu \mathrm{m}$, (-200 mesh) elek boyutlarına elenmiştir. Eleme işleminde yaklaşık $15 \mathrm{~g}$ örnek tartılarak poşetlere bırakılmış ve numaralandırılmıştır. Analiz edilecek örnekler 0,5 g olarak alınmış ve yaş kimyasal yöntem kapsamında, $90 \mathrm{~mL} \mathrm{HCl}$ $\mathrm{HNO}_{3}-\mathrm{HF}$ asit ile 1 saat çözdürülmüş ve $150 \mathrm{~mL}$ 'ye saf su ile dilute edilmiştir. Daha sonra, element içerikleri saptanmak üzere ACME Analitik Laboratuvarlarında (Acme Analytical Laboratories Ltd., Kanada) ICP-OES (Inductively Couple
Plasma-Optic Emission Spectrometre) ile analiz edilmiştir. Analiz cihaz1, Chen ve Ma [30]'da belirtilen, EPA (Environmental Protection Agency) STD-DS5 ile, STD PD1, STD2, STDGS311-1, STD GS910 STDSO-18 ve STD DS 9 standartları kullanılarak kalibre edilmiştir. Analitik veri kalitesi, söz konusu standart kulanımı ile yapılan kalibrasyonlar ile analizlerin doğruluğu ve her on örnekte bir örneğin analizinin tekrarlanması ile Eş. 1 ile kesinlik değeri $\pm 0,05$ olarak hesaplanmıştır.

$\%$ kesinlik=Standart sapma/Xortx 100

\subsection{Sediman Örneklerinin İzotop Analiz Yöntemleri (Isotope Analysis Methods of Sediment Samples)}

Nehir sediman örnekleri kimyasal analizler için Fırat Nehri akım yönü boyunca Keban- Karakaya Barajı arasından 40 farklı noktadan alınmıştır. Sr/Nd izotop analiz örnekleri ise, ilk 10 sediman arasından bir örnek olmak üzere, toplam üç 
örnek (F7), (F12) ve (F40) örnek noktalarından alınmış stronsiyum ve neodmiyum izotop jeokimya analizleri ODTÜ Jeokimya Laboratuvarlarında yapılmıştır (Şekil 2). ODTÜ Merkez Laboratuvarı (Ar-Ge Eğitim ve Ölçme Merkezi, Radyojenik İzotop Laboratuvar1)'nda Köksal ve Göncüoğlu [31], detayları ve koşulları verilen metodlardan uyarlanmış olan TLM-ARG-RIL-01 (Sr İzotop Oranı Analizi Deney Talimat1) ve TLM-ARG-RIL-02 (Nd İzotop Oranı Analizi Deney Talimatı) uygulanarak yapılmıştır. Her bir kayaç pudrası örneğinden yaklaşık $80 \mathrm{mg}$ tartılarak PFA şişelere aktarılmıştır. Örnekler, $4 \mathrm{~mL} \% 52 \mathrm{HF}$ içinde 4 gün süreyle $160^{\circ} \mathrm{C}^{\prime}$ lik 1 siticı tabla üzerinde bekletilerek tamamen çözülmüştür. Isıtıcı tabla üzerinde kurutulan örnekler önce 4 mL $6 \mathrm{~N} \mathrm{HCl}$ içinde bir gün süreyle çözülmüştür. Örnekler daha sonra tekrar 1sıtıcı tabla üzerinde buharlaştırılıp kurutularak $1 \mathrm{~mL}$ 2,5 N HCl içine alınmış ve kromatografiye hazır duruma getirilmiştir. Stronsiyum elementi, 2,5 N HCl asitle $2 \mathrm{~mL}$ hacimde Bio Rad AG50 W-X8, 100-200 mesh reçine kullanılarak teflon kolonlarda ayrılmıştır. Stronsiyumun toplanmasından sonra $6 \mathrm{~N} \mathrm{HCl}$ ile nadir toprak elementleri fraksiyonu toplanmıştır. Stronsiyum, tek Re-filamentleri üzerine Ta-aktivatör ve $0,005 \mathrm{~N} \mathrm{H}_{3} \mathrm{PO}_{4}$ kullanılarak yüklenmiş ve statik modda ölçülmüştür. ${ }^{87} \mathrm{Sr} /{ }^{86} \mathrm{Sr}$ verileri ${ }^{86} \mathrm{Sr} /{ }^{88} \mathrm{Sr}=0,1194$ 'e normalize edilmiştir. Ölçümler sırasında Sr NBS 987 standardı 0,710251 \pm 5 (n=2) kullanılmıştır. Neodmiyum elementi, diğer nadir toprak elementlerinden $0,22 \mathrm{~N} \mathrm{HCl}$ asit kullanılarak, teflon kolonlarda, $2 \mathrm{~mL}$ hacimde HDEHP (bis-ethyexyl fosfat) kaplı biobeads -Bio Rad- reçineden geçirilerek ayrılmıştır. Ayrilan neodmiyum, 0,005 $\mathrm{N} \mathrm{H}_{3} \mathrm{PO}_{4}$ ile birlikte $\mathrm{Re}$ filamente yüklenmiş, çift filament tekniği kullanılarak statik modda ölçülmüştür. Analizler sırasında, ${ }^{143} \mathrm{Nd} /{ }^{144} \mathrm{Nd}$ verileri ${ }^{146} \mathrm{Nd} /{ }^{144} \mathrm{Nd}=0,7219$ ile normalize edilmiş, Nd LaJolla standard 1 ise $0,511848 \pm 5(n=2)$ kullanılmıştır. Stronsiyum ve Nd izotop oranı ölçüm sonuçları üzerinde herhangi bir düzeltme yapılmamıştır. Ölçümler, Triton Termal İyonizasyon Kütle Spektrometresi (Thermo-Fisher) kullanılarak çoklu-toplama ile yapılmıştır. Analitik belirsizlikler 2 sigma düzeyindedir.

\subsection{Su Örneklerinin Kimyasal Analiz Yöntemleri} (Chemical Analysis Methods of Water Samples)

Nehir suyu örnekleri (FS1'den FS 35'e kadar), sediman örnek lokasyonlarının hemen yakınından alınmıştır (Şekil 2). $2 \mathrm{~m}$ uzunluğunda, portatif sap monte edilmiş 1,5 L'lik geniş ağızlı polietilen şişeler ile alınan örnekler, nehir kıyısında 500 mL'lik polietilen şişelere $0,5 \mu \mathrm{m}$ membran filtre kağ $\mathrm{d}_{1}(4,5$ $\mathrm{cm}$ çapında) ile süzülerek aktarılmıştır. Örnekler, analiz edilinceye kadar, metallerin çökelmemesi için her bir örneğe \%65'lik $10 \mathrm{~mL} \mathrm{HNO}_{3}$ ilave edilerek, pH'1 yaklaşı 3'e düşürülmüştür. Tüm su örnekleri analiz edilinceye kadar +4 ${ }^{\circ}$ C'de laboratuvarda muhafaza edilmiștir. Fırat Nehri akım yönü boyunca Keban- Karakaya Barajı arası toplam 35 adet su örneği alınmış ve Kanada ACME Laboratuvarlarında ICP-OES (Inductively Couple Plasma-Optic Emission Spectrometre) yöntemi ile analiz edilmiştir (Şekil 2). Daha sonra, elde edilen analiz sonuçları farklı istatistik programları kullanılarak sayısal verilerden kurtarılıp, literatür kapsamında yorumlanarak sunulacaktır. Bu amaçla Word, Excel, Adobe Illustrator programlarından yararlanılmıştır.

\section{JEOKİMYA (GEOCHEMISTRY)}

\subsection{Bulgular (Results)}

\subsubsection{Fırat Nehri sedimanlarının element içerikleri ve dağılımları \\ (Element contents in the Euphrates River sediments and their distributios)}

Bu bölümde, elde edilen bulgular, özet istatistiksel veriler ile birlikte tablolar halinde verilmiştir. Tablo 1'de çalışılan sediman örneklerine ait ana element özet istatistik değerler ve yerkabuğu ortalamaları verilmiştir [32]. Çokluk siralamasına göre sedimanlar içerisinde $\mathrm{Fe}>\mathrm{Ca}>\mathrm{Al}>\mathrm{Mg}>\mathrm{Ti}>\mathrm{S}>\mathrm{K}>\mathrm{P}$ ve $\mathrm{Na}$ bulunmaktadır. KebanKarakaya Barajı arası tüm örnek noktalarında, Fe, Ca, Al ve $\mathrm{Mg}$ değerlerinin $>1$ olduğu görülmektedir. Ti, $\mathrm{K}, \mathrm{P}$ ve $\mathrm{Na}$ içerikleri sırasıyla $<1$ olan değerlerdir ve ilk dört örnekte (F1, $\mathrm{F} 2, \mathrm{~F} 3$ ve F4) S içeriği artarken, diğer örnekerde en düşük ana elementi işaret etmektedir. Söz konusu örnek lokasyonları Keban eski maden sahası içerisinde yer almaktadır. Ana element konsantrasyonları yer kabuğu ortalama değerler ile karşılaştırıldığında oratalama sınır değerlerin altında kaldığı görülmektedir. Tablo 2'de Firat Nehir sedimanlarına ait 40 örneğin iz element konsantrasyonuna ait özet istatistik değerler ve Vinogradov, [32]'dan alınan yerkabuğu ortalamaları verilmiştir. Çokluk sırasına göre $\mathrm{Sr}>\mathrm{Rb}>\mathrm{Th}>\mathrm{U}$ şeklinde dağılım

Tablo 1. Ana element içeriklerine ait özet istatistik değerler ve yer kabuğu ortalama değerleri (Summary of statistical values of the major element content and the average earth crust values)

\begin{tabular}{lllllll}
\hline$\%$ & Ortalama & S.Sapma & Ortanca & Maksimum & Minimum & Yer kabuğu ort. [32] \\
\hline $\mathrm{Fe}$ & 5,22 & 1,44 & 4,67 & 10,70 & 3,54 & 4,65 \\
$\mathrm{Ca}$ & 2,68 & 1,27 & 2,37 & 7,96 & 1,45 & 2,96 \\
$\mathrm{P}$ & 0,05 & 0,01 & 0,05 & 0,08 & 0,03 & 0,01 \\
$\mathrm{Mg}$ & 1,40 & 0,42 & 1,30 & 2,35 & 0,80 & 1,87 \\
$\mathrm{Ti}$ & 0,17 & 0,08 & 0,13 & 0,36 & 0,04 & 0,45 \\
$\mathrm{Al}$ & 2,22 & 0,49 & 2,16 & 3,17 & 0,94 & 8,05 \\
$\mathrm{Na}$ & 0,04 & 0,03 & 0,02 & 0,10 & 0,01 & 2,50 \\
$\mathrm{~K}$ & 0,08 & 0,03 & 0,07 & 0,22 & 0,05 & 2,09 \\
$\mathrm{~S}$ & 0,14 & 0,63 & 0,02 & 3,99 & 0,02 & 0,05 \\
\hline
\end{tabular}


gözlenmektedir. Rb hariç Sr, Th ve U değerlerini Keban eski maden alanı içerisinde birlikte artış göstermektedir (F1, F2, F3 ve F4). Söz konusu elementler ayrica F28 ve F38 nolu örnek noktalarında birlikte atmaktadır. Bu noktaların yakın çevresinde, litolojik olarak Elazı̆̆ Magmatitleri'nin granitoyitleri ile Kömürhan Ofiyolitleri'nin yüzeylediği gözlenmektedir. Bolluk sirasına göre $\mathrm{Mn}>\mathrm{Zn}>\mathrm{Cu}>\mathrm{As}>\mathrm{Pb}$ $>1$; $\mathrm{Y}$ ve $\mathrm{Zr}>1$ sediman örneklerinde diğer iz element konsantrasyonlarının üzerinde zenginleşme göstermektedir. Sediman örneklerinde $\mathrm{mg} / \mathrm{Kg}$ cinsinden miktarı belirlenen iz element içerikleri, yer kabuğu ortalama değerler ile karşılaştırıldığında, $\mathrm{Mo}, \mathrm{Cu}, \mathrm{Pb}, \mathrm{Zn}, \mathrm{Ni}, \mathrm{Co}, \mathrm{Mn}, \mathrm{As}, \mathrm{Sr}, \mathrm{Cd}$,
$\mathrm{Sb}, \mathrm{Bi}, \mathrm{V}, \mathrm{Cr}, \mathrm{W}, \mathrm{Sc}, \mathrm{Se}, \mathrm{Te}$ ve Sn bakımından 5 ila 100 kat arasında zenginleşmiş olduğu görülmektedir. Tablo 3'de Firat Nehir sedimanlarındaki $\mathrm{Au}, \mathrm{Ag}, \mathrm{Hg}$ ve $\mathrm{Pd}$ ortalama değerleri, Vinogradov, [32]'dan alınan yer kabuğu ortalama değerlerinin altında kalmaktadır.

Ancak Keban eski maden alanı yakın çevresindeki Fırat Nehir sedimanlarından alınan örneklerde (F1, F2, F3 ve F4) maksimum değerlerin, yer kabuğu ortalama değerlerinden, Au için 34,18 kat, Ag için, 12,5 kat ve $\mathrm{Hg}$ için ise 1,71 kat daha fazla olduğu belirlenmiştir. $\mathrm{Hg}$ ve $\mathrm{Ag}$ değerlerinin $\mathrm{Au}$ oranla daha fazla zenginleştiğini söylemek mümkündür.

Tablo 2. Fırat Nehir sedimanlarının iz element içerikleri $(\mathrm{mg} / \mathrm{Kg})$, yer kabuğu ortalama değerleri (Contents of trace elements in the Euphrates River sediments ( $\mathrm{mg} / \mathrm{Kg}$ ) with average of the earth crust values)

\begin{tabular}{|c|c|c|c|c|c|c|}
\hline Element & Ortalama & S. Sapma & Ortanca & Maksimum & Minimum & Yer kabuğu ort. [32] \\
\hline Mo & 0,64 & 1,41 & 0,20 & 5,90 & 0,08 & 1,1 \\
\hline $\mathrm{Cu}$ & 45,35 & 18,31 & 40,34 & 114,86 & 33,14 & 47,00 \\
\hline $\mathrm{Pb}$ & 20,78 & 61,82 & 5,12 & 308,43 & 2,68 & 16,00 \\
\hline $\mathrm{Zn}$ & 69,58 & 44,57 & 60,10 & 285,70 & 45,40 & 83,00 \\
\hline $\mathrm{Ni}$ & 51,87 & 24,12 & 52,65 & 118,00 & 18,40 & 58,00 \\
\hline Co & 24,81 & 6,32 & 23,15 & 39,00 & 15,80 & 18,00 \\
\hline Mn & 673,13 & 174,48 & 660,00 & 1166,00 & 435,00 & 10,00 \\
\hline As & 12,07 & 10,40 & 7,80 & 52,90 & 5,40 & 1,70 \\
\hline $\mathrm{U}$ & 0,55 & 0,31 & 0,40 & 1,90 & 0,20 & 2,50 \\
\hline $\mathrm{Sr}$ & 100,04 & 58,28 & 78,40 & 378,10 & 57,20 & 340 \\
\hline $\mathrm{Cd}$ & 1,20 & 6,68 & 0,10 & 42,38 & 0,05 & 0,13 \\
\hline $\mathrm{Sb}$ & 0,85 & 2,52 & 0,46 & 16,27 & 0,05 & 0,50 \\
\hline $\mathrm{Bi}$ & 0,25 & 0,48 & 0,05 & 2,19 & 0,02 & 0,009 \\
\hline $\mathrm{V}$ & 190,20 & 91,57 & 170,50 & 456,00 & 99,00 & 90,00 \\
\hline $\mathrm{Cr}$ & 63,50 & 23,76 & 57,25 & 128,50 & 32,70 & 83,00 \\
\hline $\mathrm{Ba}$ & 44,11 & 23,84 & 35,75 & 147,90 & 23,00 & 650,00 \\
\hline B & 4,73 & 1,60 & 4,50 & 8,00 & 1,00 & 12,00 \\
\hline W & 3,88 & 7,35 & 0,20 & 20,40 & 0,10 & 1,30 \\
\hline $\mathrm{Sc}$ & 8,98 & 2,39 & 8,50 & 15,20 & 4,60 & 10,00 \\
\hline $\mathrm{Tl}$ & 0,05 & 0,09 & 0,03 & 0,59 & 0,02 & 1,00 \\
\hline $\mathrm{Se}$ & 0,13 & 0,09 & 0,10 & 0,50 & 0,10 & 0,05 \\
\hline $\mathrm{Te}$ & 0,03 & 0,04 & 0,02 & 0,25 & 0,02 & 0,001 \\
\hline $\mathrm{Ga}$ & 5,90 & 1,09 & 5,45 & 8,40 & 4,50 & 19,00 \\
\hline Cs & 0,48 & 0,21 & 0,43 & 0,88 & 0,19 & 3,70 \\
\hline $\mathrm{Ge}$ & 0,11 & 0,03 & 0,10 & 0,20 & 0,10 & 1,40 \\
\hline $\mathrm{Hf}$ & 0,25 & 0,10 & 0,26 & 0,52 & 0,08 & 1,00 \\
\hline $\mathrm{Nb}$ & 0,07 & 0,05 & 0,06 & 0,28 & 0,02 & 20,00 \\
\hline $\mathrm{Rb}$ & 3,50 & 1,96 & 3,25 & 11,80 & 1,50 & 150 \\
\hline $\mathrm{Sn}$ & 0,65 & 0,71 & 0,50 & 4,70 & 0,30 & 2,50 \\
\hline $\mathrm{Ta}$ & 0,05 & 0,00 & 0,05 & 0,05 & 0,05 & 1,00 \\
\hline $\mathrm{Zr}$ & 6,96 & 3,10 & 6,85 & 13,20 & 2,50 & 170,00 \\
\hline $\mathrm{Y}$ & 9,99 & 2,13 & 10,34 & 14,19 & 6,10 & 29,00 \\
\hline
\end{tabular}

Tablo 3. Fırat Nehir sedimanlarındaki metal içerikleri $(\mu \mathrm{g} / \mathrm{Kg})$ ve yer kabuğu ortalama değerleri (Contents of trace elements in the Euphrates River sediments ( $\mathrm{mg} / \mathrm{Kg}$ ) with average of the earth crust values)

\begin{tabular}{lllllll}
\hline & Ortalama & S. Sapma & Ortanca & Maksimum & Minimum & Yer kabuğu ortalama değ. [32] \\
\hline $\mathrm{Ag}$ & 58,59 & 186,27 & 15,00 & 877,00 & 4,00 & 70 \\
$\mathrm{Au}$ & 7,84 & 29,35 & 1,00 & 147,40 & 0,20 & 4,3 \\
$\mathrm{Hg}$ & 26,20 & 27,03 & 17,00 & 142,00 & 5,00 & 83 \\
$\mathrm{Pd}$ & 10,00 & 0,00 & 10,00 & 10,00 & 10,00 & 13 \\
$\mathrm{Pt}$ & 2,18 & 0,68 & 2,00 & 5,00 & 2,00 & - \\
\hline
\end{tabular}




\subsubsection{Nd-Sr isotope jeokimyası analiz bulgulart}

(Nd-Sr isotope geochemistry analysis results)

$\mathrm{Bu}$ çalışma kapsamında üç örnekte (F7, F12 ve F40) Sr ve $\mathrm{Nd}$ izotop bileşim oranları; nehir sedimanlarının farklı üç lokasyondaki orijinini belirleyebilmek amaciyla kullanılmıştır. Goldstein ve Jacobsen [20], sedimanlardaki izotopik bileşimler arasındaki farklılığın mineraller arasındaki alterasyon durumlarını ortaya koymada önemli olduğunu ve ana nehir sistemleri içerisinde element ve partiküllerin taşınmasının, kimyasal ve mekanik alterasyon yoluyla olduğunu bu nedenle, sedimanların tașınma proseslerinin anlaşılabileceğini belirtmektedir. Tablo 4'de Firat Nehri akım yönü boyunca F7, F12 ve F40 kodlu örnek noktalarında ${ }^{143} \mathrm{Nd} /{ }^{144} \mathrm{Nd}$ izotop bileşim değerinin 0,512654 ; 0,512836 ve $0,512775 \mathrm{ile},{ }^{87} \mathrm{Sr} /{ }^{86} \mathrm{Sr}$ değerinin ise sirasiyla 0,$7053 ; 0,7048$ ve 0,7057 ve Eş. 1'e göre hesaplanan $\mathrm{ENd}(0)$ değerleri ise, sirasiyla $0,35,3,90$ ve 2,70 olarak belirlenmiştir.

$E N d(0)={ }^{143} \mathrm{Nd} /{ }^{144} \mathrm{Nd}$ (Ölçülen/Measured)/0,512636-1x10 $0^{4}$ Hensel vd. ve McDonough vd. [33, 34]. Martin vd. [35] göre hesaplanmış 1000/Sr değerleri 16,11, 13,74 ve 13,17 olarak belirlenmiştir. $\mathrm{Bu}$ değerlerin, Hensel vd. [33]'den alınan, bazaltik toprak, meta-sedimanter toprak, meta-grovak ve ortalama sedimanlardan yüksek olduğu görülmektedir. Fırat
Nehri akım yönü boyunca örneklerin tamamında $\mathrm{Nd}$ ve $\mathrm{Sr}$ içeriklerinin $>1$ olduğu görülmektedir. Ancak her iki element içeriği yinede yer kabuğu ortalama değer aralığında kalmaktadır. Bununla birlikte, F16 nolu örnek noktasında en yüksek $\mathrm{Sr}$ ve $\mathrm{Nd}$ değerleri dikkat çekmektedir. F16 örnek noktasının litolojik özelliklerinin (granodiyoritik kayaçların) sediman kimyası üzerindeki etkisini göstermektedir.

\subsubsection{Nehir sediman örneklerindeki bazı metaller ve arseniğin sediman kalite standart değerlendirmesi \\ (Evaluation of sediment quality standards for some metals and arsenic in the river sediment samples)}

Tablo 5'de Fırat Nehri sedimanları içerisindeki bazı metaller ve As için Eş. 2'de hesaplanan eşik değer ile literatür kapsamında belirlenen, eşik etki değeri (TEL), olasılı etki seviyesi (PEL), en düşük etki değeri (LEL), minimal etki eşik değeri (MET), düşük etki aralığı (ERL), eşik etki konsantrasyonu (TEC) ve olas1li etki konsantrasyonu (PEC) değerleri ile karşılaştırılmıştır [36, 37]. Tablo 5'e göre, eşik etki bileşim değerleri ve sediman kalite değerlendirme kriterleri bakımından, $\mathrm{As}, \mathrm{Cd}, \mathrm{Cu}, \mathrm{Ni}, \mathrm{Hg}$ ve $\mathrm{Ag}$ değerlerinin eşik etki bileşim değerlerinin üzerinde kaldığ anlaşılmaktadır.

Eşik Değer $=X($ aritmetik ortalama $)+2 \sigma($ standart sapma $)$

Tablo 4. Firat Nehir sediman örneklerinde Sr ve Nd izotop bileşim oranları ile $E N d$ ve 1000/Sr değerleri *: Hensel vd.

[33] ( $\mathrm{Sr}$ and $\mathrm{Nd}$ isotope composition ratio of the Euphrates sediment samples ENd and 1000/Sr values *: Hensel et al [33])

\begin{tabular}{lllll}
\hline Örnek Kodlar1 & ${ }^{143} \mathrm{Nd} /{ }^{144} \mathrm{Nd}$ & ${ }^{87} \mathrm{Sr} /{ }^{86} \mathrm{Sr}$ & $\mathrm{\varepsilon Nd}(0)$ & $1000 / \mathrm{Sr}$ \\
\hline F7 & 0,512654 & 0,7053 & 0,35 & 16,11 \\
F12 & 0,512836 & 0,7048 & 3,9 & 13,74 \\
F40 & 0,512775 & 0,7057 & 2,7 & 13,17 \\
\hline Basaltic Soil* & 0,711783 & 0,705603 & 2,26 & 3,9 \\
Metased. soil* & 0,512501 & 0,709646 & -2.67 & 6,57 \\
Metagrovak* & 0,512847 & 0,705374 & 4,08 & 2,49 \\
Sedimanlar* & 0,512805 & 0,704583 & 3,26 & 4,0 \\
\hline
\end{tabular}

Tablo 5. Fırat Nehir sedimanlarındaki bazı metallerin, ortalama ve eşik değerleri ile çeşitli etki değeri (The average and threshold values of some metals in the Euphrates River sediments and the various effect levels)

\begin{tabular}{llllllllll}
\hline & & $\begin{array}{l}\text { Firat Nehir } \\
\text { Sedimanları }\end{array}$ & $\begin{array}{l}\text { Eşik Etki Yoğunluğu (Threshold } \\
\text { effect concentration) }[36,37]\end{array}$ & $\begin{array}{l}\text { Sedimman Kalite } \\
\text { Değerlendirme Kriterleri } \\
{[36,37]}\end{array}$ \\
\hline Element & Medyan & $\begin{array}{l}\text { Eşik } \\
\text { Değer=Xort+2 } \\
\text { standart sapma }\end{array}$ & PEL & TEL & LEL & MET & ERL & PEC & TEC \\
\hline $\mathrm{As}$ & 7,8 & 15,75 & 17 & 5,9 & 6 & 7 & 33 & 33 & 9,8 \\
$\mathrm{Cd}$ & 0,10 & 6,00 & 3,53 & 0,6 & 0,6 & 0,9 & 5 & 1 & 5 \\
$\mathrm{Cr}$ & 57,25 & 63,07 & 90 & 37,3 & 26 & 55 & 80 & 43 & 110 \\
$\mathrm{Cu}$ & 40,34 & 45,28 & 197 & 35,7 & 16 & 28 & 70 & 32 & 150 \\
$\mathrm{~Pb}$ & 5,12 & 13,62 & 91,3 & 35 & 31 & 42 & 35 & 36 & 130 \\
$\mathrm{Ni}$ & 52,65 & 49,01 & 36 & 18 & 120 & 35 & 30 & 23 & 49 \\
$\mathrm{Zn}$ & 60,1 & 65,98 & 315 & 123 & 0,2 & 150 & 120 & 120 & 460 \\
$\mathrm{Hg}$ & 17 & 22,87 & 0,486 & 0,174 & - & 0,2 & 0,15 & 1,06 & 0,18 \\
$\mathrm{Ag}$ & 15 & 28,83 & - & - & - & - & - & 1,1 & 2,2 \\
$\mathrm{Co}$ & 23,15 & 26,41 & - & - & - & - & - & 50 & - \\
\hline
\end{tabular}




\subsubsection{Su örneklerine ait analitik bulgular \\ (Analytical results of the water samples)}

Firat Nehri su örnekleri, Frrat Nehri boyunca 1 nolu kum örneğinin alındığı noktadan itibaren Karakaya Baraj Gölü'ne kadar 35 farklı noktadan alınmış ve kimyasal analiz sonuçları Tablo 6'da verilmiştir. Fırat Nehir su örneklerinin ortalama ve medyan değerleri yüzey su element içerikleri ile karşılaştırıldığında, $\mathrm{Al}, \mathrm{Fe}, \mathrm{P}, \mathrm{Si}$ ve $\mathrm{Zn}$ dışında diğer elmentlerin ortalama değerlerinin normal sınırlar içerisinde olduğu görülmektedir. Bazı örnek noktalarındaki $\mathrm{Al}, \mathrm{Ca}, \mathrm{Cd}$, $\mathrm{Cu}, \mathrm{Fe}, \mathrm{Mg}, \mathrm{Mn}, \mathrm{P}, \mathrm{Rb}, \mathrm{Pb}, \mathrm{Si}$ ve $\mathrm{Zn}$ içeriklerinin standart yüzey suyu değerlerinden yüksek olduğu görülmektedir. Fırat Nehir suyunun ağır metaller bakımından, Gediz Nehri metal içeriğinden [40] daha düşük değerlere sahip olduğu; EPA [41] ve TSE [42] değerleri ile karşılaştırıldığında ise; Cd'un 44,60; Pb'un 5,40; Zn'nun 24,4; Cr'un 5,2; 9,52; Cu'nn ise 1,6 ve 3,57 kat daha düşük değerlere sahip olduğu görülmektedir.

DL: Dedeksiyon Limiti (DL: Detection Limit)

\subsubsection{Firat Nehir sedimetleri ve suları arasındaki etkileşimler \\ (The interactions between sediment and water in the Euphrates River)}

Hem su hem de sediman örneklerinde hesaplanan eşik değerlere göre hazırlanan anomali haritaları karşılaştırıldığında, nehir sedimanları içerisindeki V derişimi 1 nolu örnek noktasından başlayarak, 33 nolu örnek noktasına kadar devam etmektedir. Oysaki su örneklerinde, $\mathrm{V}$ sadece 7 nolu örnek noktasında su içerisinde eşik değer üzerindedir. $\mathrm{Sr}, \mathrm{Ba}, \mathrm{Mn}$ ve $\mathrm{Zn}$ değerleri hem su hem de sediman içerisinde akım yönü boyunca birlikte aynı dağılımı göstermektedir. $\mathrm{Cr}$ ve $\mathrm{Pb}$ sedimanlar içerisinde 1 nolu örnekten başlayarak 35 nolu örneğe doğru homojen dağılım malesef suda görülmemekte ve su işerisinde sadece S7-S10; S7-S11 örneklerinde yüksek değer vermektedir. Mo ise hem nehir sedimanlarında hem de su içerisinde diğer bütün metallere göre en az taşınan metal olup sadece, 1, 2, 3 nolu nehir sedimanlarında ve 2 nolu su örneğinde yüksek değer vermiştir. Tablo 2 ve Tablo 6; B, Ba, Cr ve Zr'un hem su hemde sediman içerisindeki konsantrasyonunu

Tablo 6. Furat Nehir suyu element içeriklerine ait özet istatistik değerler $(\mu \mathrm{g} / \mathrm{L} ; * \mathrm{mg} / \mathrm{L})$

(Summary of statistical values for concentration of elements in Euphrates River water $\left(\mu \mathrm{g} / \mathrm{L} ;{ }^{*} \mathrm{mg} / \mathrm{L}\right)$

\begin{tabular}{|c|c|c|c|c|c|c|}
\hline Elements & Medyan & Ortalama & Standart Sapma & Maksimum & $\begin{array}{l}\text { Yeralt1 Suyu } \\
\text { Ort. [38] }\end{array}$ & $\begin{array}{l}\text { Yüzey suyu } \\
\text { 1. sinıf-4. sinıf [39] }\end{array}$ \\
\hline $\mathrm{Al}$ & 157 & 174,46 & 139 & 509 & - & $1,5-75$ \\
\hline As & 3,60 & 10,09 & 35,12 & 211,60 & $25 \mathrm{EQ}$ & $10-360$ \\
\hline B & 118,00 & 131,26 & 30,41 & 236,00 & 200 eq & - \\
\hline $\mathrm{Ba}$ & 38,23 & 37,71 & 21,07 & 146,99 & 100 eq & - \\
\hline $\mathrm{Ca}^{*}$ & 49,70 & 61,27 & 58,77 & 390,64 & $200000 \mathrm{~B}$ & $10-100$ \\
\hline $\mathrm{Cd}$ & 0,05 & 0,31 & 1,43 & 8,51 & 5 eq & $0,07-0,53$ \\
\hline $\mathrm{Cl}^{*}$ & 21,00 & 18,69 & 6,29 & 29,00 & $20000 \mathrm{eq}$ & $250000 y$ \\
\hline $\mathrm{Co}$ & 0,25 & 0,35 & 0,39 & 2,18 & 0,1 & 1 \\
\hline $\mathrm{Cr}$ & 2,10 & 2,93 & 2,68 & 11,80 & $30 \mathrm{eq}$ & $1-16$ \\
\hline $\mathrm{Cu}$ & 5,60 & 19,87 & 42,61 & 180,80 & $30 \mathrm{eq}$ & $2-18$ \\
\hline $\mathrm{Hg}$ & $<\mathrm{DL}$ & $<\mathrm{DL}$ & $<\mathrm{DL}$ & $<\mathrm{DL}$ & $1 \mathrm{eq}$ & $0,003-2,4$ \\
\hline $\mathrm{Fe}$ & 178,00 & 251,63 & 387,98 & 2301,00 & $200 \mathrm{~A}$ & 300 \\
\hline $\mathrm{K}^{*}$ & 1,96 & 2,10 & 1,59 & 9,93 & $5000 \mathrm{eq}$ & - \\
\hline $\mathrm{La}$ & 0,11 & 0,21 & 0,43 & 2,63 & 0,2 & - \\
\hline $\mathrm{Li}$ & 6,90 & 6,51 & 3,78 & 25,10 & 3 & - \\
\hline Mg* & 20,40 & 24,60 & 20,85 & 140,80 & 50000 & $50^{\mathrm{a}}$ \\
\hline $\mathrm{Mn}$ & 20,43 & 55,65 & 141,67 & 643,74 & 300EQS & 0,05 \\
\hline Mo & 1,60 & 2,02 & 1,17 & 7,60 & 30000 & - \\
\hline $\mathrm{Na}^{*}$ & 24,10 & 26,17 & 4,85 & 39,11 & $150000 \mathrm{eq}$ & 20 \\
\hline $\mathrm{Nd}$ & 0,15 & 0,15 & 0,10 & 0,38 & 0,08 & - \\
\hline $\mathrm{P}$ & 837,00 & 994,46 & 1182,23 & 5352,00 & 20 & - \\
\hline $\mathrm{Pb}$ & 0,50 & 2,33 & 3,77 & 14,50 & 3 & $0,1-82$ \\
\hline $\mathrm{Rb}$ & 1,31 & 2,06 & 4,17 & 25,57 & 1 & - \\
\hline $\mathrm{S}^{*}$ & 15,00 & 24,97 & 61,32 & 377,00 & 30000 & - \\
\hline $\mathrm{Sb}$ & 0,70 & 1,73 & 2,20 & 8,40 & 16 & - \\
\hline $\mathrm{Si}$ & 2292,00 & 4501,49 & 4499,87 & 12193,00 & 400 & - \\
\hline $\mathrm{Zn}$ & 5,00 & 333,57 & 888,69 & 4294,00 & $100 \mathrm{eq}$ & $45-120$ \\
\hline $\mathrm{Zr}$ & 0,07 & 0,09 & 0,12 & 0,73 & - & - \\
\hline
\end{tabular}


göstermektedir. $\mathrm{Ba}, \mathrm{Zr}$ ve $\mathrm{Cr}$ gibi ağır metallerin sediman içerisinde, konsantrasyonunun, su içerisindekinden daha yüksek değerlerde olduğu, ancak $\mathrm{B}$ ise su içerisindeki konsantrasyonunun, sediman içerisinden daha yüksek olduğunu göstermektedir. Bu durum ağır metallerin mekanik ve B ise hidromorfik olarak taşındığını açıkça ortaya koymaktadır. Şekil 3a'da sediman ve su içerisindeki $\mathrm{Mo}, \mathrm{Cu}$, $\mathrm{Pb}, \mathrm{Zn}, \mathrm{Ni}, \mathrm{Co}, \mathrm{Mn}, \mathrm{As}, \mathrm{U}, \mathrm{Sr}, \mathrm{Cd}, \mathrm{Sb}, \mathrm{Bi}, \mathrm{Mn}, \mathrm{V}, \mathrm{Sc}, \mathrm{Tl}, \mathrm{Se}$, $\mathrm{Te}, \mathrm{Ga}$ ve $\mathrm{Cs}$ dağılımları karşılaştırılmıştır. Cr'un, sedimanlarda artarken su içerisinde azalmışolduğu, B ise sedimanlarda azalırken su içerisinde arttığı görülmektedir. Şekil 3b'de ise, Hf ve Zr gibi ağır metallerin dışında sediman içerisindeki konsantarasyon ile su içerisindeki konsantrasyon arasında uyumlu artış gözlemlenmektedir.

\section{SONUÇLAR VE TARTIŞMALAR (RESULTS AND DISCUSSIONS)}

Fırat Nehir sedimanlarında yüksek $\mathrm{Ca} / \mathrm{Na}$ oranları, Ca'un kırıntılı karbonatlar içindeki yüksek konsantrasyonu ile ilgili olmalıdır. Ayrıca, Ca ve Na düşük iyonik potansiyellerinden dolayı diğer elementlere göre çözünürlükleri yüksek olmasına rağmen partiküller üzerine adsorbe olabilme yani affiniteleri düşük elementlerdir. Dolayısı ile sedimanlar içerisindeki konsantrasyonları, oldukça çeşitli etkenlere bağlı olmalıdır, örneğin iyon değişim ve adsorbsiyon durumları gibi. Fırat Nehir sedimanları içerisindeki Al ve $\mathrm{Mg}$ konsantrasyonları, bölgesel litolojik birimlerin ayrışması sonucu oluşan, çeşitli bileşimli kil mineralleri ile ilgili olmalıdır. Goldstein ve Jacobsen [20], sedimanları izotopik bileşimler arasındaki farklılığın mineraller arasındaki alterasyon durumlarını orataya koymada önemli olduğunu ve ana nehir sistemleri içerisinde element ve partiküllerin taşınmasının, kimyasal ve mekanik alterasyon yoluyla olduğunu bu nedenle, sedimanların taşınma proseslerinin anlaşlabileceğini belirtmektedir. Fırat Nehri akım yönü boyunca F7, F12 ve F40 kodlu örnek noktalarında ${ }^{143} \mathrm{Nd} /{ }^{144} \mathrm{Nd}$ izotop bileşim değerinin $0,512654,-0,512836$ ve 0,$512775 ;{ }^{87} \mathrm{Sr} /{ }^{86} \mathrm{Sr}$ değerinin ise sirasiyla, $0,7053-0,7048$ ve $0,7057, \varepsilon N d(0)$ değerleri ise, sirasiyla $0,35-3,90$ ve 2,70 olarak belirlenmiştir. Fırat Nehir sediman örneklerindeki ${ }^{87} \mathrm{Sr} /{ }^{86} \mathrm{Sr}-\mathrm{Ca} / \mathrm{Sr}$ ve $\mathrm{Sr}$ bileşimleri, Gaillardet vd. [21] dikkate alındığında, subtropikal iklimin hakim olduğu Fırat Nehir yatağında evaporitik sedimanların yoğun olduğu
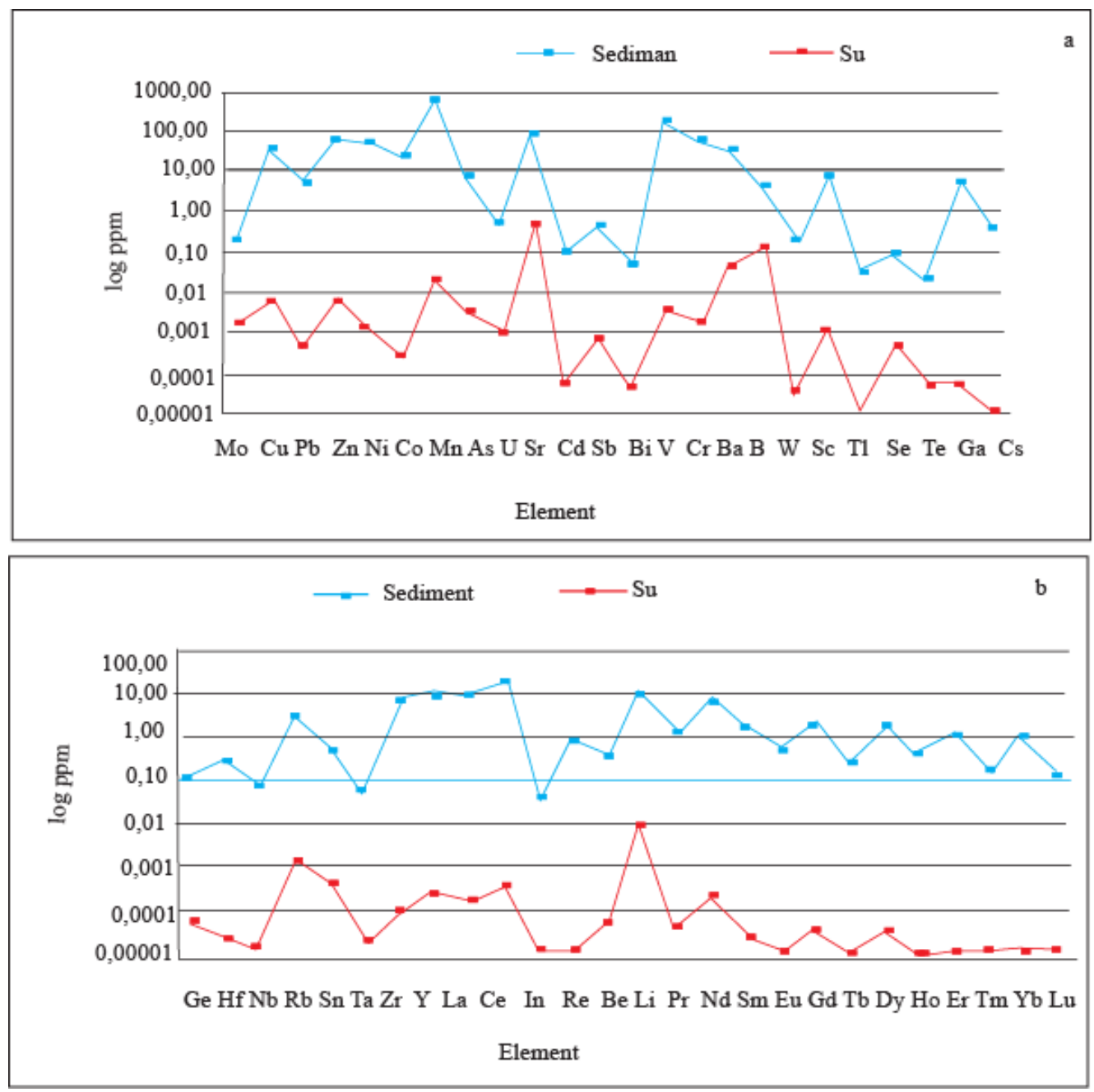

Şekil 3. a ve b: Bazı metal ve NTE'nin sediman ve su içerisindeki dağılımı ( $a$ and $b$ : Distribution of REE and some metals in sediment and water samples) 
gözlenmektedir. Hesaplanmış $E N d$ değerleri (sırasıyla $0,35-$ 3,90 ve 2,70) ile Rolland vd. [22] ve Hensel vd. [33] çalışmalarında, sırasıyla Naomi bölgesinden alınan sediman ve New England Granitoidleri, metapelitik kayaçlar ve metagraovaklar ile karşılaştırıldığında, Firat Nehir sedimanların özellikle analizi yapılan, $-75 \mu \mathrm{m}$ tane boyundaki örneklerin pozitif $\mathrm{ENd}$ değerlerinden dolayı, karbonatlı sulardan çökelme yolu ile zenginleşmiş olabileceği düşünülmektedir. Burke vd. [23], çalışmasında, Jura-Kretase yaşlı sedimanlarda ${ }^{87} \mathrm{Sr} /{ }^{86} \mathrm{Sr}$ değerlerinin $0,707-$ 0,708 aralığında değiştiğini belirtmektedir. Bu izotopik veriler, sediman bileşimi üzerinde iki farklı kaynağın etkili olduğunu göstermiştir. Bussy [24] yaptığ 1 çalışmada, MontBlanc graniti ile ilişkili Arve Nehir sedimanlarda ${ }^{87} \mathrm{Sr} /{ }^{86} \mathrm{Sr}$ değerinin 0,728 olduğunu, ancak karbonatca zengin kayaçlarda bu oranın daha düşük olduğunu saptamıştır (yaklaşık 0,704). Bu durum, Fırat Nehir sedimanlarının sadece magmatik kayaçların ayrışması ile değil aynı zamanda Keban Metamorfik kayaçlardaki metakarbonatların Fırat Nehir sediman bileşimi üzerinde etkili olduğunu düşündürmektedir. Fırat Nehir sedimanlardaki, ${ }^{143} \mathrm{Nd} /{ }^{144} \mathrm{Nd}-{ }^{87} \mathrm{Sr} /{ }^{86} \mathrm{Sr}$ değerleri, aynı zamanda New England granitoidlerinin bileşim alanına girmektedir. $\mathrm{Bu}$ durumda karbonatlı meta-sedimanlar ile Elazığ Magmatitleri'nin granitik kayaçlarının ayrışması ile Fırat Nehir sedimanlarının bileşimi oluşmuş olmalıdır. Yüksek $\mathrm{Ba} / \mathrm{Rb}$ oranı $\mathrm{Ba}$ derişiminin, Keban polimetalik cevherleşme alanından kaynaklı olabileceğini ve Ba'ca zengin hidrotermal çözeltilerin, Keban Metamorfitleri içerisindeki konumundan kaynaklanmış olabileceği düşünülmektedir. Çalışma alanı içerisindeki Fırat Nehir sedimanlarında, medyan değeri $\mathrm{Al}(\% 2,22)$ olarak belirlenmiştir. Bu oran üst kıtasal kabukla karşılaştırıldığında $(\% 8,05)$, 4 katı düşük olduğu anlaşılmaktadır. Bu durum, nehir yatağı içerisindeki partiküllerde $\mathrm{Al}$ zengin kil oranının nispeten düşük olduğu anlamına gelmektedir. $\mathrm{Bu}$ durum, partikül boyutunun element zenginleşmesi üzerindeki etkiyi ortaya koymaktadır $[43,44]$. Bu çalışma kapsamında düşük Ti değerleri $(<\% 1)$, Ti'ın kimyasal ayrışma süreci içerisinde nispeten diğer elementlere oranla immobil olmasından kaynaklanmış olmalıdır. P değerleri, granitik veya felsik magmatik kayaçlardan kaynaklı apatitlerin ayrışması yolu ile sedimanlar içerisinde $\mathrm{Ti}$ ile birlikte zenginleşebilmektedir [45]. Major element sınıfinda bulunan \%S değerleri, Keban polimetalik maden sahası içerisinde yer almaktadır. Kalender [46], sülfürün kaynağının magmatik kökenli olduğu anlaşılmaktadır. Magmatik kaynaklı hidrotermal çözeltilerin, neden olduğu cevherleşmelerin ayrışması sonucu Fırat Nehir sedimanları, Fırat Nehri akım yönü boyunca bu bölgede sülfürce zenginleşmektedir. Firat Nehir akım yönü boyunca farklı litolojik birimler içerisinden geçmesi, sedimanlarının iz element bileşiminin farklı örnek noktalarında değişim göstermesine neden olmaktadır. Demirak vd. [47], Gediz Nehri sediman, su ve balık dokularında $\mathrm{Cd}, \mathrm{Zn}, \mathrm{Cr}, \mathrm{Cu}$ ve $\mathrm{Pb}$ konsantrasyonlarının başlıca nedeninin nehir suyunun bu elementlerce zengin olması, diğer taraftan, asidik yeraltı suyu akım yönünü, bu suların düşük oranda çözülmüş oksijen ve yüksek oranda $\mathrm{SO}_{4}$ içermesi metallerin akım yönü boyunca taşınması üzerinde etkili olduğu belirtilmektedir. Cr ve V diğer bazı iz elementlere göre daha ağır metaller grubuna girmektedir. Sediman içerisindeki konsantrasyonları mafik yada bazik bileşimli çevre kayaçlardaki Cr spinel, kromit ve manyetit veya çalışma alanının güneyinde yeralan ofiyolitlerin ayrışması ve sediman bileşimi içerisine katılması ile ilgili olmalıdır [48]. Firat Nehiri kıyı sedimanlardaki, V/Ni $(190,20 / 51,87=3,66)$ oranı vanadyum içeriğine bağlı olarak artmaktadır. Bazı araştırmalara göre, bu oran, indirgeyici koşullara bağlı olarak sedimanlar içerisinde artabilmektedir [49]. Cr, Hf ve $\mathrm{Zr}$ gibi ağır metaller, sedimanlar içerisinde zenginleşme gösterirken aynı elementlerin nehir suyu içerisindeki konsantrasyonlarının azalması, söz konusu elementlerin diğer elementlere göre, alkali sularda çözünürlüklerinin daha düşük yani immobil olduklarını göstermektedir. Ayrıca, bu metallerin, mekanik olarak sedimanlar içerisinde zenginleşmiş olabileceği söylenebilir. $\mathrm{Bu}$ çalışma kapsamında üç örnekte (F7, F12 ve F40) Sr ve $\mathrm{Nd}$ izotop oranları belirlenmiş ve bu sonuçlar kullanılarak; nehir sedimanların bileşimine katkı sağlayan, farklı üç noktadaki, kaynak kayacın kökenini belirleyebilmek amacıyla kullanılmıştır.

\section{SONUÇLAR (CONCLUSIONS)}

İnceleme alanı drenaj sistemi içerisinde, element derişimi üzerinde etkili olan en önemli faktörlerden biri bölgesel litolojik özelliklerdir. Jeokimyasal veriler, Fırat Nehir sedimanları içerisindeki yüksek $\mathrm{Al}$ ve $\mathrm{Mg}$ konsantrasyonlarının, bölgesel litolojik birimlerin ayrışması sonucu oluşan, çeşitli bileşimli kil minerallerinden (kaolin ve simektit) kaynaklanıyor olmalıdır. Fırat Nehiri'nin, akım yönü boyunca farklı litolojik birimler içerisinden geçmesi, nehir sedimanlarının, iz element konsantrasyonlarının, farklı örnek noktalarında değişim göstermesine neden olmaktadır. Hesaplanan logaritmik eşikdeğerlere göre anomali oluşturan bazı iz elementlerin (Örneğin; $\mathrm{Ag}, \mathrm{As}, \mathrm{Au}, \mathrm{Ba}, \mathrm{Cu}, \mathrm{Hg}, \mathrm{Mn}$, $\mathrm{Mo}, \mathrm{Pb}$ ve $\mathrm{Zn}$ ) konsantrasyonlarının bölgedeki polimetalik mineralizasyonlardan ve terkedilmiş maden sahasındaki pasaların ayrışmasından kaynaklandığ yanında, Firat Nehir sedimanlarının ${ }^{143} \mathrm{Nd} /{ }^{144} \mathrm{Nd} 0,512654-$ 0,512836 aralığı, granitoidlerin bileşim alanına girmektedir. ${ }^{87} \mathrm{Sr} /{ }^{86} \mathrm{Sr}$ 0,7048-0,7057 aralığ 1 ise Sr kaynağının, karbonatlı meta-sedimanter olduğunu işaret etmektedir. $\mathrm{Bu}$ nedenle, Fırat Nehir sediman bileşimleri üzerinde, Elazı ̆ Magmatitleri'nin granitik kayaçlarının ve Keban Metamorfitleri'nin meta-karbonatlarının ayrışmasının etkili olduğunu söylemek mümkündür. ${ }^{87} \mathrm{Sr} /{ }^{86} \mathrm{Sr}$ izotop bileşim oranı ile $\mathrm{Ca} / \mathrm{Sr}$ oranlarının korelasyonu, Firat Nehir yatağında çökelen sedimanların, subtropikal iklim koşullarında gelişen evaporitik oluşumlara işaret etmektedir.

\section{TEŞEKKÜR (ACKNOWLEDGEMENT)}

$\mathrm{Bu}$ çalışma, Fırat Üniversitesi Bilimsel Projeleri Destek Birimi (FÜBAP) tarafından MF.14.26 nolu Proje kapsamında desteklenmiştir. Yazarlar desteklerinden dolayı teşekkürlerini sunarlar. 


\section{KAYNAKLAR (REFERENCES)}

1. Yılmaz Y., Yiğitbaş E., Yıldırım M., Genç Ş.C., Güneydoğu metamorfik masiflerinin kökeni, Türkiye 9. Petrol Kongr. Bild., 296-306, 1992.

2. Özgül N. ve Turşucu A., Stratigraphy of the Mesozoic carbonate sequence of the Munzur Mountains (Eastern Taurus), In: Tekeli O. ve Gncüoğlu, M.C., eds., On the Geology of the Taurus Belt., Ankara, 223-228,1984.

3. Yazgan E., Geodynamic evolution of the Eastern Taurus region (Malatya- Elazığ area, Turkey), Int. Symp. On the Geology of the Taurus Belt., Ankara, proceedings, 199-208, 1984.

4. Aksoy E., Elazığ batı ve güneyinin genel jeolojik özellikleri, Türk Yerbil. Derg., 1 (1), 113-123, 1993.

5. Bingöl A.F., Elazığ-Pertek-Kovancılar arası volkanik kayaçların petrolojisi, F.Ü Fen Fakültesi Dergisi, 1, 921, 1982.

6. Bingöl A.F., Geology of the Elazığ area in the Eastern Taurus region, Int. Symp. On the geology of the Taurus Belt, Bildiriler, 209 -216, Ankara,1984.

7. İnceöz M., Harput Elazığ yakın kuzeyi ve doğusunun jeolojik özellikleri, Doktora Tezi, F.Ü. Fen Bilimleri Enstitüsü, Elazığ, 1994.

8. Bingöl A.F., Petrographical and petrological features of the intrusive rocks of Yüksek Complex in the Elazı $\breve{g}$ region (Eastern Taurus- Turkey), Jour. Firat Univ., 3 (2), 1-17, 1988.

9. Bingöl A.F. ve Beyarslan M., Elazı̆̆ Magmatitleri'nin jeokimyas1 ve petrolojisi, 30. Y1 Sempozyumu bildirileri, KTÜ, 208-227, Trabzon, 1996.

10. Dumanlılar H., İspendere (Malatya) ve çevresindeki cevherleşmelerin incelenmesi, Yüksek Lisans Tezi, A.Ü. Fen Bilimleri Enstitüsü, Ankara (yayımlanmamış), 1998.

11. Dumanlılar Ö., Baskil Elazığ civarındaki granitoid kayaçlarına bağlı cevherleşmelerin incelenmesi, Doktora Tezi, A.Ü. Fen Bilimleri Enstitüsü, Ankara (yayımlanmış), 2002.

12. Akgül B. ve Bingöl A.F., Piran köyü Keban çevresindeki Magmatit kayaçların petrografik ve petrojenetik özellikleri, Selçuk Üniv. Müh-Mim. Fak., 20. Y11 Jeoloji Semp. Bildirileri, 13-14, 1997.

13. Türkmen İ., Elazı̆̆ Doğusunda Çaybağı Formasyonu (Üst Miyosen- Pliyosen) Stratigrafisi ve Sedimantolojisi, Türkiye Jeoloji Bülteni, 34 (21), 45-53, 1991.

14. Cook J.A., Andrew S.M., Johnson, M.S., Lead, Zinc, cadmium and fluoride small mammals from contaminated grass-land established on fluorspar tailings, Water, Air Soil Poll, 51, 43-54, 1990.

15. Kalender L., Environmental impact and drainage geochemistry of the abandoned Keban $\mathrm{Ag}, \mathrm{Pb}, \mathrm{Zn}$ deposit, In: Dionisions Panagiotaras (Ed.), Working Maden $\mathrm{Cu}$ Deposit and Alpine Type Cr Deposit in the Eastern Anatolia, Turkey. Geochemistry. Published by In Tech, Croatia, 345-370 (www.intechopen.com), 2012.
16. Romero A., Gonzalez I., Galan E., Trace elements absorption by citrus in a heavily polluted mining site, $\mathrm{J}$ Geochem Explor,, 113, 76-85, 2013.

17. Singh M., Ansari A.A., Muller G., Singh I.B., Heavy metals in freshly deposit sediments of Gomti river (a tributary of the Ganga river):effects of human activities, Environ. Geol, 29, 246-252, 1997.

18. Kalender L. ve Aytimur G., REE geochemistry of Euphrates River, Turkey, J Chem, 1, 1-13, 2016.

19. Kalender L. ve Çiçek Uçar S., Assessment of Metal Contamination in Sediments in The Tributaries of the Euphrates River, Using Pollution Indices and the Determination of the Pollution Source, Turkey, J Geochem Explor, 134, 73-84, 2013.

20. Goldstein S.J. ve Jacobsen S.B., The Nd and Sr Isotopic Systematics of River-Water Dissolved Material: Implications For The Sources of Nd And Sr In Seawater, Chem Geol, (Isotope Geoscience Section), 66, 245-272, 1987.

21. Gaillardet J., Dupre B., Allegre C.J., Negrel P., Chemical and physical denudation in the Amazon river basin, Chem Geol,, 142, 141-173, 1997.

22. Rolland M.R., Arnurd F., Chapron E., Desmet M., Givelet N., Alibert C., McCulloch M., Sr and $\mathrm{Nd}$ isotopes as tracers of clastic sources in Lake Le Bourget sediment (NW Alps, France) during the Little Ice Age: Palaeohydrology implications, Chem Geol, 224, 183200, 2005.

23. Burke W.H., Denison R.E., Hetherington E.A., Koepnick R.B., Nelson H.F., Otto J.B., Variation of seawater ${ }^{87} \mathrm{Sr} /{ }^{86} \mathrm{Sr}$ throughout Phanerozoic time, Geology, 10, 516- 519, 1982.

24. Bussy F., Pe'trogene'se des enclaves microgrenues associe'es aux granitoides calco-alcalins: exemple des massifs varisque du Mont-Blanc (Alpes occidentales) et mioce'ne du Monte Capanne (Ile d'Elbe, Italie), Mem. Ge'ol. Lausanne, 7, 309, 1990.

25. Yazgan E. ve Chessex R., Geology and tectonic evolution of the southeastern Taurides in the region of Malatya, TPJD Bült, 3, 1-42, 1991.

26. Beyarslan M., Kömürhan Ofiyolit Birimi'nin petrografik ve petrolojik incelenmesi, Doktora Tezi, F.Ü. Fen Bilimleri Enstitüsü, Elazı̆̆ (Yayınlanmamış), 1996.

27. Beyarslan M. ve Bingöl A.F., Petrology of a SupraSubduction Zone Ophiolite (Elazığ, Turkey), Can. J. Earth Sci., 37, 1411-1424, 2000.

28. MTA Genel Müdürlüğü., Türkiye Jeoloji Haritas1-İzmir, Ankara, 2002.

29. Kalender L. ve Bölücek C., Environmental Impact and Drainage Geochemistry in The Vicinity of the Harput $\mathrm{Pb}-\mathrm{Zn}-\mathrm{Cu}$ Veins, Elazı̆g, Se Turkey, Turk J Earth Sci, 16, 241-255, 2007.

30. Chen M. ve Ma L.Q., Comparison of EPA Digestion Methods for Metal Analysis Using Certified and Florida Soils, J Environ. Qual, 27 ( 6), 1294-1300, 1998.

31. Köksal S. ve Göncüoğlu M.C., Sr and $\mathrm{Nd}$ Isotopic Characteristics of Some S, I and A-Type Granitoids 
From Central Anatolia, Turk J Earth Sci, 17, 111-127, 2008.

32. Vinogradov A.P., Average contents of chemical elements in the principal types of igneous rocks of the Earth's crust, Geochemistry, 7, 641-664, 1962.

33. Hensel H. D., McCulloch M. T., Chappell B. W., The New England Batholith: Constraints on its derivation from $\mathrm{Nd}$ and $\mathrm{Sr}$ isotopic studies of granitoids and country rocks, Geochim Cosmochim Acta, 49, 369-384, 1985.

34. McDonough W.F., McCulloch M.T., Sun S.S., Isotopic and geochemical systematics in Tertiary-Recent basalts from southeastern Australia and implications for the evolution of the sub-continental lithosphere, Geochim Cosmochim Acta, 49, 2051-2067, 1985.

35. Martin M.W., Friedrich A.M., Bowring S.A., Shortlived continental magmatic arc at Connemara, western Irish Caledonides: Implications for the age of the Grampian orogeny, Department of Earth, Atmospheric, and Planetary Sciences, Massachusetts Institute of Technology, Cambridge, Massachusetts 02139, USA, 1999.

36. MacDonald D.D., Ingersoll C.G., Berger T.A., Development and Evaluation of Consensus-Based Sediment Quality Guidelines for Freshwater Ecosystems, Arch Environ Contam Toxicol, 39, 20-31, 2000.

37. Persaud D.R., Jaagumagi R., HaytonA., Guidelines for the protection and management of aquatic sediments in Ontario, Standards Development Branch. Ontario Ministry of Environment and Energy. Toronto, Canada,1993.

38. NRA, Water Quality Objectives. Procedures Used by the National Rivers Authority for the Purpose of the Surface Waters (River Ecosystem) (Classification) Regulation, 1994.

39. Enderlein S., Rainer E., Peter W., National Rivers authority, England and Wales, Bristol, Surface Water Quality Standards, 62-302, 2010.
40. Bakac M. ve Kumru M.N., Factor analysis in the geochemical studies along the Gediz River, Turkey, J Radioanal Nucl Chem, 249 (3), 617-624. 2001.

41. Turkish Environmental Guidelines (TSE)., Publications of Turkish Foundation of Environment, 1988.

42. US EPA, National Recommended Water Quality Criteria Correction Office of Water, EPA 822-Z-99-001, 25, 1999.

43. McLennan S.M., Taylor S.R., Scott M., The geochemical evolution of the continental crust, Rev Geophys, 33 (2), 241-265, 1995.

44. Hossain I., Roy K.K., Biswas P.K., Alam M., Moniruzzaman M., Deeba F., Geochemical characteristics of Holocene sediments from Chuadanga district, Bangladesh: Implications for weathering, climate, redox conditions, provenance and tectonic setting, Chin J Geochem, 33, 336, 2014.

45. Hayashi K., Fujisawa H., Holland H.D., Ohmoto H.,"Geochemistry of $1.9 \mathrm{Ga}$ sedimentary rocks from northeastern Labrador, Canada [J]", Geochim Cosmochim Acta, 61, 4115-4137, 1997.

46. Kalender L., Oxygen, Carbon and Sulphur Isotope Studies in the Keban $\mathrm{Pb}-\mathrm{Zn}$ Deposits, Eastern Turkey: An Approach on the Origin of Hydrothermal Fluids, J African Earth Sci, 59, 341-348, London, 2011.

47. Demirak A., Yilmaz F., Tuna L., Ozdemir N., Heavy metals in water, sediment and tissues of Leuciscus cephalus from a stream in southwestern Turkey, Chemosphere, 63,1451-1458. 2005.

48. Wronkiewicz D.J. ve Condie K.C., Geochemistry of Archean shales from the Witwatersrand Supergroup, South Africa: Source-area weathering and provenance, Geochim Cosmochim Acta., 51, 2401-2416, 1987.

49. Koca D., Sarı A., Koç Ş., Yavuz B., Koralay D.B., Example for major and trace element enrichment in marine source rock from Turkey: Akkuyu Formation (Middle Taurus), Journal of the Faculty of Engineering and Architecture of Gazi University, 25 (2), 243-256, 2010. 
